\title{
Trends of Ulnar Collateral Ligament Reconstruction in the United States from 2003 to 2014: Analysis of 3,133 Patients
}

\author{
Olumuyiwa A. Idowu, M.D., Haroutioun H. Boyajian, M.D., Kevin Lindsay-Rivera, M.D.,
} Cody S. Lee, M.D., Michael J. Lee, M.D., Lewis L. Shi, M.D., and Aravind Athiviraham, M.D.

\begin{abstract}
Purpose: The purpose of this study is to investigate the trends concerning ulnar collateral ligament (UCL) reconstruction (UCLR) for athletic injuries within the United States over the years 2003 to 2014. Methods: A retrospective review of the Truven Health Marketscan ${ }^{\circledR}$ Commercial Database was conducted for patients undergoing UCLR. Data was reviewed for patients treated between 2003 and 2014, and the cohort of patients undergoing UCLR was queried using Common Procedural Terminology code 24346. Patients ages 11 to 40 years were included and divided into 6 different age groups, with the rate of UCLR calculated for each group. Results: The overall rate of UCLR increased from 4.4 per million in 2003 to 11.9 per million in $2014(p<.01)$. Throughout the same time period, the rate per million increased from 3.3 to 22.1 in 11 - to 15 -year-olds $(p<.01)$, from 105.4 to 293.2 in 16- to 20 -year-olds $(p<.01)$, from 23.1 to 67.0 in 21 - to 25 -year-olds $(p<.01)$, and from 2.1 to 5.7 in $31-$ to 35 -year-olds $(p<.01)$. There was no significant increase in the rate of UCLR in the age groups of 26 to 30 and 36 to 40 years. Conclusion: UCLR was mostly performed in patients aged 11 to 25 years $(96.6 \%)$, and specifically most common in those patients aged 16 to 20 years $(67.4 \%)$. The rate of UCLR procedures increased over time for younger age groups significantly more than for their older counterparts. Clinical Relevance: UCLR rates are increasing in young patients despite efforts addressing injury risk reduction strategies and education for coaches, players, and parents regarding risk factors for UCL injury.
\end{abstract}

$\mathbf{T}$ he ulnar collateral ligament (UCL) is a primary elbow stabilizer and critical for valgus stability of the joint. ${ }^{1}$ The ligament originates at the posterior distal aspect of the medial epicondyle and inserts into the base

From the Department of Orthopaedic Surgery, Keck Medicine of USC, Los Angeles, California, U.S.A. (O.A.I.); the Department of General Surgery, Henry Ford Wyandotte Hospital, Wyandotte, Michigan, U.S.A. (H.H.B.); and the Department of Orthopaedic Surgery and Rehabilitation Medicine, University of Chicago Medicine and Biological Sciences, Chicago, Illinois, U.S.A. (K.L.-R., C.S.L., M.J.L., L.L.S., A.A.)

The authors report the following potential conflicts of interest or sources of funding: M.J.L. reports personal fees from DePuy Synthes, Globus Medical, Stryker. L.L.S. reports personal fees from DePuy Synthes. Full ICMJE author disclosure forms are available for this article online, as supplementary material.

Received November 7, 2019; accepted May 13, 2020.

Address correspondence to Aravind Athiviraham, MD, Department of Orthopaedic Surgery and Rehabilitation Medicine, University of Chicago Medicine and Biological Sciences, 5841 S. Maryland Avenue, MC 3079, Chicago, IL 60637.E-mail: aathiviraham@bsd.uchicago.edu

(C) 2020 THE AUTHORS. Published by Elsevier Inc. on behalf of the Arthroscopy Association of North America. This is an open access article under the CC BY-NC-ND license (http://creativecommons.org/licenses/by-nc-nd/4.0/). 2666-061X/191368

https://doi.org/10.1016/j.asmr.2020.05.005 of the medial coronoid process. It is composed of 3 bands: anterior, posterior, and transverse. UCL injuries are most commonly due to repetitive overhead throwing motions that transmit valgus stress to the anterior band of the UCL. ${ }^{2}$ Less frequently, these injuries are due to traumatic stress to the elbow during a fall on an outstretched hand that may cause dislocation of the elbow, as well as rupture of the UCL.

Jobe et al. ${ }^{3}$ first described successful surgical treatment for these injuries in 1986. Since that time, not only has the technique been modified, but the surgery, colloquially called Tommy John surgery, has also gained widespread media attention for its connection to professional baseball and its perceived ability to improve the pitching velocity of these top-tier athletes. ${ }^{4}$ Although the procedure has been proven to aid in return to sport for these athletes, evidence has demonstrated that the pitching velocity of these athletes actually remains the same or decreases slightly. ${ }^{5}$ Despite this, there has been a steady increase in the number of ulnar collateral ligament reconstructions (UCLRs) done for MLB pitchers, denoting the procedure's popularity and perceived effectiveness. ${ }^{6}$

Public perception of this surgery has grown even more within the United States, as athletes are engaging 
Table 1. Inclusion: Common Procedural Terminology (CPT) Codes

\begin{tabular}{|c|c|}
\hline CPT Code & Description \\
\hline 24346 & $\begin{array}{l}\text { Repair medial collateral ligament, } \\
\text { elbow, with tendon graft, } \\
\text { including graft harvest }\end{array}$ \\
\hline 64718 & $\begin{array}{l}\text { Neuroplasty and/or transposition; } \\
\text { ulnar nerve at elbow }\end{array}$ \\
\hline $\begin{array}{l}29830,29834,29835,29836, \\
\quad 29837,29838\end{array}$ & Arthroscopy of elbow \\
\hline
\end{tabular}

in competitive sports at increasingly younger ages and devoting more time year-round to these endeavors. Furthermore, it is well documented that overuse in the form of increased playing time per year and increased pitches per game is the main cause of UCL injury. ${ }^{7}$ In fact, in a single surgeon's series, an alarming 11 -fold increase was noted in UCLRs performed on high school pitchers between 1998 and 2003. ${ }^{8}$

The aim of this study is to investigate the trends concerning UCLR for athletic injuries within the United States over the years 2003 to 2014. We hypothesize that the overall rate of UCLRs will increase over the specified time period, and the younger age groups will demonstrate a higher increase in the rate relative to their older counterparts.

\section{Methods}

A retrospective review of the Truven Health MarketScan ${ }^{\circledR}$ Commercial Database was conducted for patients undergoing UCLRs. This database houses deidentified records for $\sim 55$ million patients in the United States $<65$ years old with private or employer-provided coverage, spanning 2003 to 2014. The database contains 7 tables, including inpatient admission, facility header, inpatient service, outpatient service, population, outpatient pharmaceutical claims, and enrollment. The inpatient services and outpatient services tables were used in this study. Records include, among other information, general demographics, payer data, International Classification of Diseases, Ninth Revision diagnosis codes, billed costs for medications and office visits, and claims for Current Procedural Terminology (CPT) codes with associated dates. This study received no external funding and, given the deidentified nature of the dataset, was exempted from review by the institutional review board.

Data were reviewed for patients treated between 2003 and 2014, and the cohort of patients undergoing UCLR was queried using the CPT code 24346 (Table 1). Patients ages 11 to 40 years were included, to minimize the possibility of UCLRs performed for congenital deformities and nonathletic injuries.

The frequency of the CPT code 24346 was identified per year, and then the rate of the procedure per million was calculated relative to the number of patients enrolled in the database per year. The trend of the mean age of the patients was analyzed and plotted over the decade spanning the study time interval, along with the percentage of surgeries having concomitant ulnar nerve decompression and utilization of arthroscopy. Patients were divided into 6 different age groups: 11 to 15,16 to 20,21 to 25,26 to 30,31 to 35 , and 36 to 40 years. The population of each age group in the database per year was collected, and the rate of UCLR was calculated in each group annually, along with the percentage of the surgery each group represents during each year. Patients who underwent any type of fracture or dislocation procedures on the humerus, proximal radius, or the elbow along with the UCLRs were excluded (Table 2).

Logistic regression models were used to analyze the significance of the trends over the years. All analyses used SAS 9.3 and SPSS. Significance was set at $p<.05$ for all statistical testing.

\section{Results}

Included in the study were 3,133 patients, 2,791 males $(89.1 \%)$ and 342 females $(10.9 \%)$. The mean age of the sample was $19.1 \pm 4.1$ years. The overall rate of UCLR increased from 4.4 per million in 2003 to 11.9 per million in $2014(p<.001)$ (Fig 1). Throughout the same time period, the rate per million increased from 3.3 to 22.1 in the age group of 11 to 15 years $(p<.01)$, from 105.4 to 293.2 in the age group of 16 to 20 years $(p<.01)$, from 23.1 to 67.0 in the age group of 21 to 25 years $(p<.01)$, and from 2.1 to 5.7 in the age group of 31 to 35 years $(p<.01)$. There were no significant increases in the rates of UCLR in the age groups of 26 to 30 or 36 to 40 years (Fig 2).

Table 2. Exclusion: Common Procedural Terminology (CPT) codes

\begin{tabular}{|c|c|}
\hline CPT Code & Description \\
\hline 24685 & $\begin{array}{c}\text { Open treatment of ulnar fracture proximal end (olecranon } \\
\text { process), with or without internal or external fixation }\end{array}$ \\
\hline 24666 & $\begin{array}{l}\text { Open treatment of radial head or neck fracture, with or } \\
\text { without internal fixation or radial head excision; with } \\
\text { radial head prosthetic replacement }\end{array}$ \\
\hline 24575 & $\begin{array}{l}\text { Open treatment of humeral epicondylar fracture, medial } \\
\text { or lateral, with or without internal or external fixation }\end{array}$ \\
\hline 24366 & Arthroplasty, radial head, with implant \\
\hline 24586 & $\begin{array}{l}\text { Open treatment of periarticular fracture and/or dislocation } \\
\text { of the elbow (fracture distal humerus and proximal ulna } \\
\text { and/or proximal radius) }\end{array}$ \\
\hline 24120 & $\begin{array}{l}\text { Excision or curettage of bone cyst or benign tumor; radial } \\
\text { head or neck or olecranon process }\end{array}$ \\
\hline 24579 & $\begin{array}{l}\text { Open treatment of humeral condylar fracture, medial or } \\
\text { lateral, with or without internal or external fixation }\end{array}$ \\
\hline 24140 & Partial excision, humerus \\
\hline 20680 & $\begin{array}{l}\text { Removal of implant; deep, eg, buried wire, pin, screw, } \\
\text { metal band, nail, rod or plate) removal of hardware }\end{array}$ \\
\hline 24665 & $\begin{array}{l}\text { Open treatment of radial head or neck fracture, with or } \\
\text { without internal fixation or radial head excision }\end{array}$ \\
\hline
\end{tabular}


Trend of UCLRs Performed

Fig 1. Trend of overall ulnar collateral ligament (UCL) reconstructions performed from 2003 to 2014.

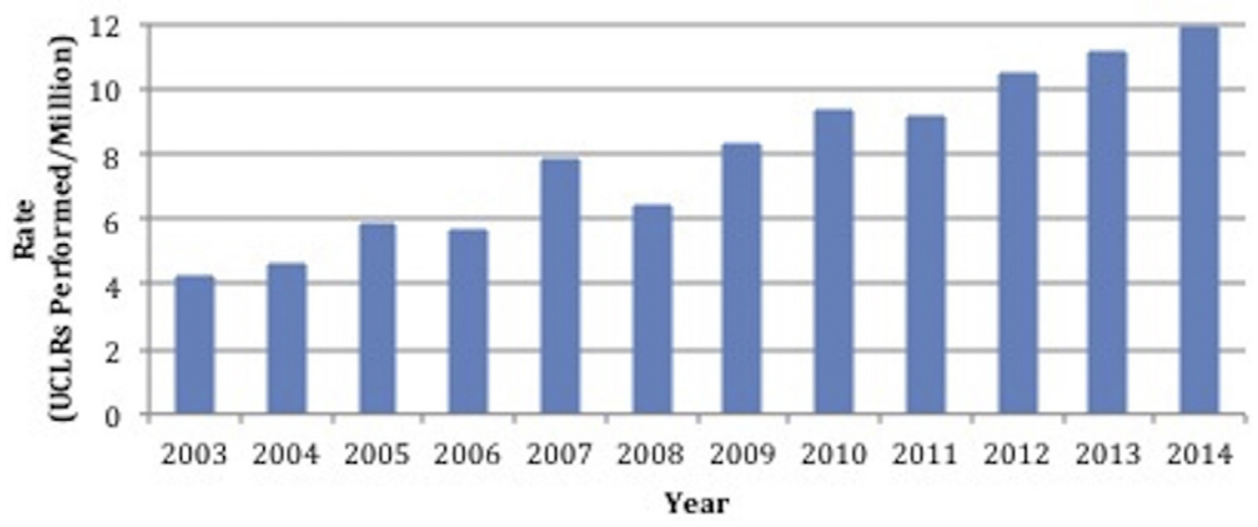

There were $298(9.5 \%)$ patients in the age group 11 to 15 years; $2,222(70.9 \%)$ in the age group 16 to 20 years; $509(16.2 \%)$ in the age group 21 to 25 years; and the remaining $104(3.3 \%)$ in the older age groups $(26$ to 40 years). From 2003 to 2014 , the percentage of UCLRs represented by the age group 11 to 15 years increased from $4.6 \%$ to $10.2 \%$, and from $11.0 \%$ to $17.1 \%$ in the age group 21 to 25 years, but decreased from $76.6 \%$ to $67.4 \%$ in the age group 16 to 20 years, from $3.1 \%$ to $1.5 \%$ in the age group 26 to 30 years, from $3.1 \%$ to $1.7 \%$ in the age group 31 to 35 years, and from $1.6 \%$ to $1.5 \%$ in the age group 36 to 40 years (Fig 3).

Overall, $1,340(42.8 \%)$ patients underwent ulnar nerve transposition, and $330(10.5 \%)$ patients underwent arthroscopic surgery during UCLR. The mean age of the sample did not significantly decrease from 2003 to $2014(p=.18)$. There was an increase in percentage of utilization of ulnar nerve transposition from $31.3 \%$ in 2003 to $47.8 \%$ in 2014 , but it was not significant $(p=.20)$ (Fig 4). Finally, percentage utilization of arthroscopy throughout the time period oscillated, and there was no significant trend ( $p=.34$ ) (Fig 5).

\section{Discussion}

Our study demonstrated an increase in the rate of the surgery by a factor of almost 2.7 , from 4.4 per million in 2003 to 11.9 per million in 2014, a result that is compatible with those of the previous investigations. $^{9-11}$ After stratifying the study population by age, 3,029 patients $(96.7 \%)$ were $<25$ years old. Moreover, the rate of UCLR only increased in the age groups of 11 to 15,16 to 20,21 to 25 , and 31 to 35 years. Although statistically significant, the rate of increase in the 31- to 35-year olds was not clinically important. These results might reflect the current sports

\section{Total UCLRs Performed By Age}

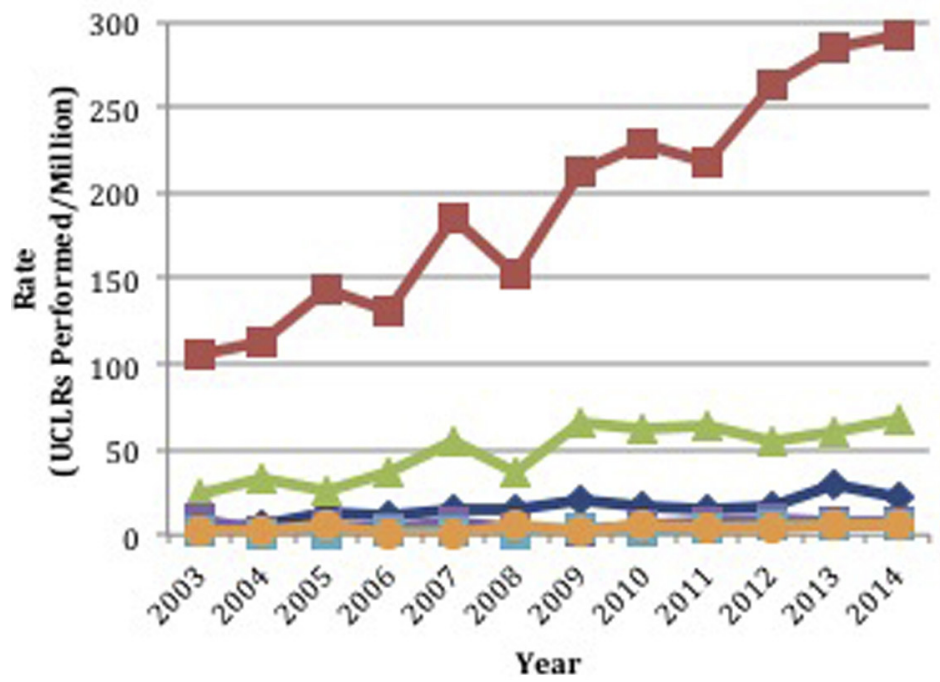

$=11-15(P<0.01)$

- $16-20(P<0.01)$

$=21-25(\mathrm{P}<0.01)$

-26-30 ( $\mathrm{P}=0.47)$

$=31-35(\mathrm{P}<0.01)$

$36.40(P=0.14)$
Fig 2. Rate per million relative to age from 2003 to 2014 . 


\section{Breakdown of Total UCLRs Performed by Age}

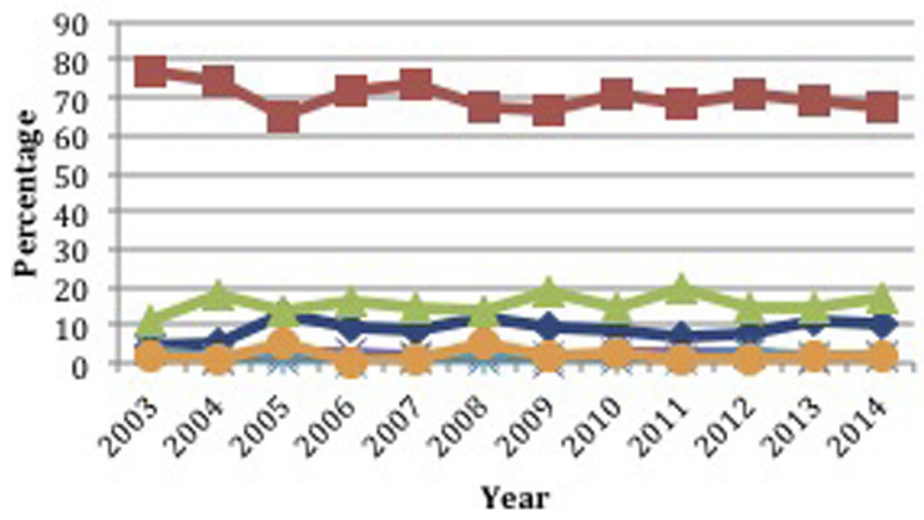

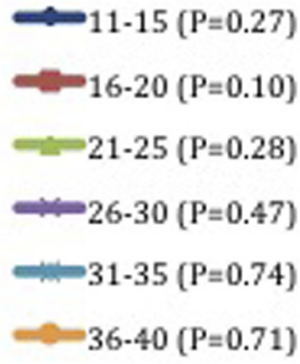

Fig 3. Percentage of ulnar collateral ligament (UCL) reconstructions relative to age from 2003 to 2014 . culture within the United States, in which younger athletes are participating in competitive baseball tournaments year-round, thus throwing more frequently and increasing the risk for UCL injury. ${ }^{12}$ To combat this, the Little League Baseball and Softball organization introduced pitch count restrictions in 2006 to limit the number of practice and competitive pitches that an athlete may throw on the basis of age and to encourage appropriate rest from throwing relative to the number of pitches thrown. ${ }^{13}$ These guidelines were revisited and expanded into the Pitch Smart program in 2014. ${ }^{14}$ Despite guidelines like these having been around since 2006, the data in this article, as well as previous research, suggest that these guidelines are not followed strictly or are inadequate.

The success rate of UCLR, along with the successful return of Major League Baseball players to regular play, may also be contributing to the nonadherence of young athletes to current protective throwing guidelines. Perpetuating the nonadherence to these guidelines and the rise of UCLR rate within the young population is the misconception and uninformed nature of the coaches, players, and players' parents about the risk factors for UCL injuries. In a survey given to highschool baseball teams, $31 \%$ of coaches, $28 \%$ of players, and $25 \%$ of players' parents did not believe the number of pitches thrown to be a risk factor for UCL reconstruction, and $30 \%$ of coaches, $51 \%$ of players, and $37 \%$ of parents believed surgery should be performed in the absence of elbow injury to enhance performance. ${ }^{4}$ Misconceptions regarding UCLR also exist in the media. In a survey of 516 members of the sports media, only $48.4 \%$ believed that pitch counts could help prevent UCL injuries, and $25 \%$ believed that UCLR was primarily done for enhancing athletic performance. $^{15}$

Another possible reason for the increase in UCLR procedures could relate to increased availability of those providing surgery. Hodgins et al. ${ }^{10}$ reported that there was a significant increase in the number of medical centers performing UCLR in the state of New York, rising from 10 medical centers in 2002 to 20 in 2011 . This might be attributed to a greater number of advanced, fellowship-trained surgeons in UCLR, enhanced experience of surgeons with UCLR, and the availability of improved instrumentation, which collectively make surgeons more comfortable with the procedure and results in a greater proportion of surgeons who offer operative treatment compared with earlier times. Although it is reasonable to assume that this surge in the rate of operative treatment of UCL injuries is attributed to the increase of young patients participating in competitive baseball, it might also be worth investigating whether the proper indications of operative treatment are being used to perform UCLRs and whether certain patients should be treated nonoperatively.

The initial UCLR technique, first described by Jobe et al., ${ }^{3}$ had high rates of ulnar nerve complications owing to the transposition of the ulnar nerve during surgery. However, the recently modified docking techniques and muscle-splitting approach do not include ulnar nerve transposition. ${ }^{16-18}$ This practice has reduced postoperative ulnar neuropathy from $9 \%$ to $4 \%$ and has increased the rate of excellent outcomes from $75 \%$ to $89 \% .{ }^{19}$ Watson et al. ${ }^{20}$ reported that

\section{Percentage of Ulnar Nerve Transposition Performed}

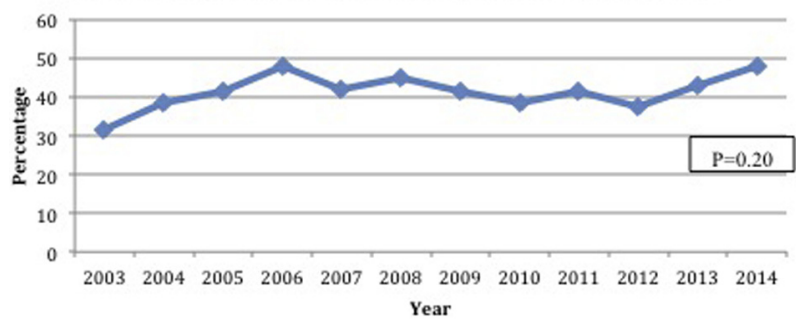

Fig 4. Percentage of concomitant ulnar nerve transposition from 2003 to 2014. 


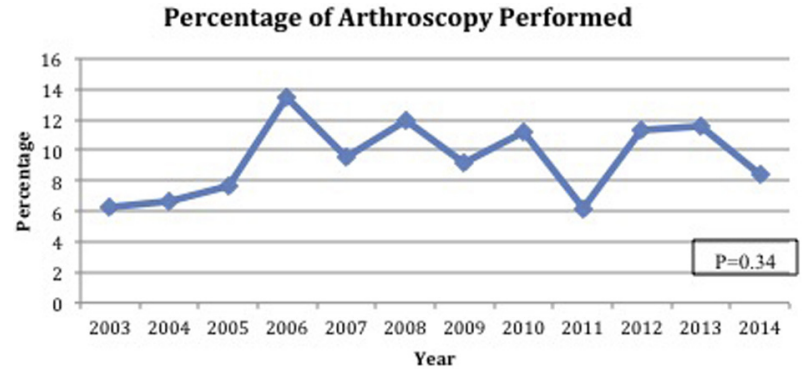

Fig 5. Percentage of concomitant arthroscopy from 2003 to 2014 .

using docking techniques yielded complication rates ranging from $0 \%$ to $5 \%$, and they recommend reserving ulnar nerve transposition for patients with preoperative neuritis. Given the current literature on these outcomes, it was expected that the rates of ulnar nerve transposition would decrease over the years, especially with a larger pool of newly trained physicians who would be more willing to align their practice with the most recent techniques of UCLR. However, there was no significant change in the rate of ulnar nerve transposition in this study. The reasons for this might be multifactorial. Although UCLR is now performed in an increasing number of institutions and by increasing number of physicians, the majority of them are still performed in few institutions and by relatively small number of physicians who have been performing UCLR for a long time, and thus may not be as willing to change their practice based on current literature. Lastly, as Hodgins et al. ${ }^{10}$ state, the addition of a procedural code to the operation provides a financial incentive for a concomitant ulnar nerve procedure, especially in an era of declining reimbursement.

The epidemiology of UCL injuries and UCLRs has been thoroughly studied within professional baseball, but, since the surgery was first described, very few studies have investigated their epidemiology and trends within the general population. ${ }^{6}$ Of the 3 studies that investigated the epidemiology and trends of this procedure, 2 of them focused on a single state, and the other focused on a relatively short period of time and did not account for cases caused by trauma. ${ }^{9-11}$ This study investigated the trend of UCLRs over a period of 12 years and excluded those patients who underwent UCLR as a secondary surgery during fracture or dislocation treatment or for a congenital deformity. Also, our study's database represents claims throughout the United States, and no geographic biases would alter the magnitude and directionality of our findings in a clinically meaningful way. Thus, we do not believe geography is of concern in the interpretation of our results. MarketScan also has a quantity of patients unmatched by most other databases in medicine, allowing for a unique analysis of the surgical procedures in question, and enabling us to discern even minor changes over time.

\section{Limitations}

Inherent to any database study are several limitations. First, any CPT code-based study relies on competent coding. The authors took several steps to minimize the effects of miscoding, but in a study of this size, some errant coding is certainly present. Second, the Marketscan ${ }^{\circledR}$ Commercial Database is limited to privately insured patients, and patients with Medicare without supplemental insurance and the uninsured are not included in the database population. Additionally, patients with lower socioeconomic status participate in fewer sporting activities and have less access to health care, and thus would have less theoretical risk of UCL injury, as well as fewer options for treatment. ${ }^{21,22}$ As such, this limits the generalizability of our study.

\section{Conclusions}

UCLR was mostly performed in patients 11 to 25 years old $(96.6 \%)$, and specifically most common in those aged 16 to 20 years $(67.4 \%)$. The rate of UCLR procedures increased over time for younger age groups, significantly more so than for their older counterparts.

\section{References}

1. Lee ML, Rosenwasser MP. Chronic elbow instability. Orthop Clin North Am 1999;30:81-89.

2. Fleisig GS, Andrews JR, Dillman CJ, Escamilla RF. Kinetics of baseball pitching with implications about injury mechanisms. Am J Sports Med 1995;23:233-239.

3. Jobe FW, Stark H, Lombardo SJ. Reconstruction of the ulnar collateral ligament in athletes. J Bone Joint Surg Am 1986;68:1158-1163.

4. Ahmad CS, Grantham WJ, Greiwe RM. Public perceptions of Tommy John surgery. Phys Sportsmed 2012;40:64-72.

5. Jiang JJ, Leland JM. Analysis of pitching velocity in major league baseball players before and after ulnar collateral ligament reconstruction. Am J Sports Med 2014;42: 880-885.

6. Wilson AT, Pidgeon TS, Morrell NT, DaSilva MF. Trends in revision elbow ulnar collateral ligament reconstruction in professional baseball pitchers. J Hand Surg 2015;40: 2249-2254.

7. Fleisig GS, Andrews JR. Prevention of elbow injuries in youth baseball pitchers. Sports Health 2012;4:419-424.

8. Petty DH, Andrews JR, Fleisig GS, Cain EL. Ulnar collateral ligament reconstruction in high school baseball players clinical results and injury risk factors. Am J Sports Med 2004;32:1158-1164.

9. Mahure SA, Mollon B, Shamah SD, Kwon YW, Rokito AS. Disproportionate trends in ulnar collateral ligament reconstruction: projections through 2025 and a literature review. J Shoulder Elbow Surg 2016;25:1005-1012.

10. Hodgins JL, Vitale M, Arons RR, Ahmad CS. Epidemiology of medial ulnar collateral ligament reconstruction: a 
10-year study in New York State. Am J Sports Med 2016;44:729-734.

11. Erickson BJ, Nwachukwu BU, Rosas S, Schairer WW, McCormick FM, Bach BR, et al. Trends in medial ulnar collateral ligament reconstruction in the United States: a retrospective review of a large private-payer database from 2007 to 2011. Am J Sports Med 2015;43:1770-1774.

12. Feeley BT, Agel J, LaPrade RF. When is it too early for single sport specialization? Am J Sports Med 2016;44:234-241.

13. Little League Baseball Communications Division. Regular season pitching rules-baseball. SouthWilliamsport, PA: Little League, 2009.

14. Pitch Smart [Internet]. Major League Baseball. [cited 2016 Nov 8]. Available from: http://m.mlb.com/pitchsmart/ pitching-guidelines/.

15. Conte SA, Hodgins JL, ElAttrache NS, Patterson-Flynn N, Ahmad CS. Media perceptions of Tommy John surgery. Phys Sportsmed 2015;43:375-380.

16. Rohrbough JT, Altchek DW, Hyman J, Williams RJ, Botts JD. Medial collateral ligament reconstruction of the elbow using the docking technique. Am J Sports Med 2002;30:541-548.
17. Smith GR, Altchek DW, Pagnani MJ, Keeley JR. A muscle-splitting approach to the ulnar collateral ligament of the elbow. Neuroanatomy and operative technique. Am J Sports Med 1996;24:575-580.

18. Cain EL, Andrews JR, Dugas JR, Wilk KE, McMichael CS, Walter JC, et al. Outcome of ulnar collateral ligament reconstruction of the elbow in 1281 athletes: results in 743 athletes with minimum 2-year follow-up. Am J Sports Med 2010;38:2426-2434.

19. Vitale MA, Ahmad CS. The outcome of elbow ulnar collateral ligament reconstruction in overhead athletes: a systematic review. Am J Sports Med 2008;36:1193-1205.

20. Watson JN, McQueen P, Hutchinson MR. A systematic review of ulnar collateral ligament reconstruction techniques. Am J Sports Med 2013:0363546513509051.

21. Pierce TR, Mehlman CT, Tamai J, Skaggs DL. Access to care for the adolescent anterior cruciate ligament patient with Medicaid versus private insurance. J Pediatr Orthop 2012;32:245-248.

22. Hyun Kim T, Samson LF, Lu N. Racial/ethnic disparities in the utilization of high-technology hospitals. J Natl Med Assoc 2010;102:803-810. 